SUPPORTING INFORMATION

\title{
Bipolar CdS/Pd Photocatalytic Membrane for Selective Segregation of Reduction and Oxidation Processes
}

Federica Costantino ${ }^{1,2,3,4}$ Luca Gavioli $^{3}$ and Prashant V. Kamat ${ }^{\star 1,2}$

${ }^{1}$ Notre Dame Radiation Laboratory, ${ }^{2}$ Department of Chemistry and Biochemistry, and University of Notre Dame, Notre Dame, Indiana 46556, United States

${ }^{3}$ Intersciplinary Laboratories for Advanced Materials Physics (i-LAMP) and Dipartimento di Matematica e Fisica, Università Cattolica del Sacro Cuore, Via della Garzetta 46, 25133 Brescia, Italy

${ }^{4}$ Smart Materials, Istituto Italiano di Tecnologia (IIT), Via Morego 30, 16163, Genova, Italy 


\section{Morphological characterization of BPM using SEM}
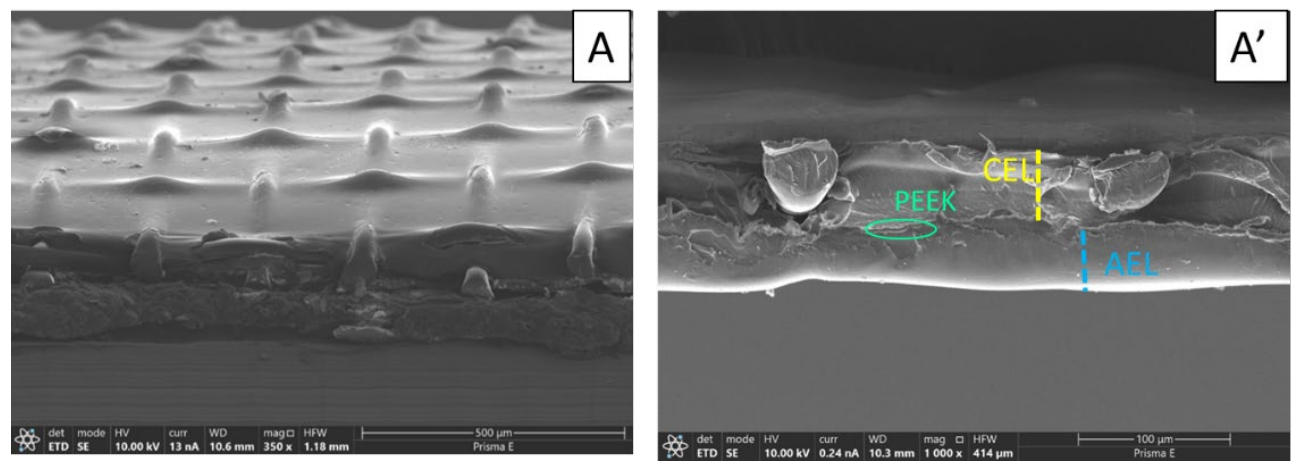

Figure S1. (A) Cross section of pristine BPM (scale bar: $500 \mu \mathrm{m}$ ) and ( $\left.A^{\prime}\right)$ high magnification analysis on BPM (scale bar: $100 \mu \mathrm{m}$ ), Both CEL side (yellow dash line) and AEL side (blue dash line) can be detected from the figure, also the junction made of poly-ethyl ketone (PEEK) of the membrane is clearly observed (green circle).
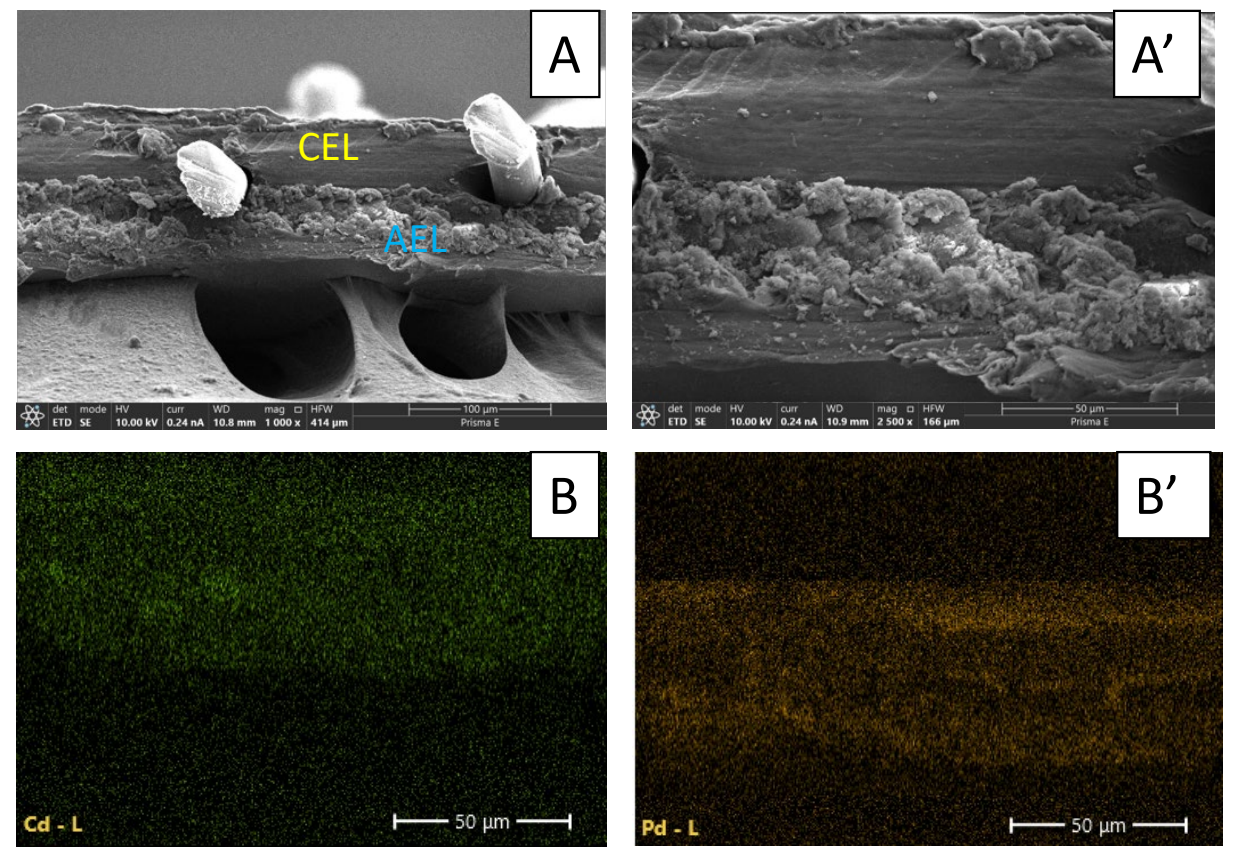

Figure S2. Cross-section of BPM-CdS/Pd (A) with lower magnification (scale bar: $100 \mu \mathrm{m}$ ) and ( $\mathrm{A}^{\prime}$ ) higher magnification (scale bar: $50 \mu \mathrm{m}$ ) respectively, in both cases the CEL and AEL side can be clearly observed. The EDX analysis confirmed the presence of Cd (top CEL part) and Pd (bottom AEL part) elements in the bipolar membrane, in accordance with the experimental procedure where the CdS is synthetized in the CEL side and Pd in the AEL side of the membrane. 


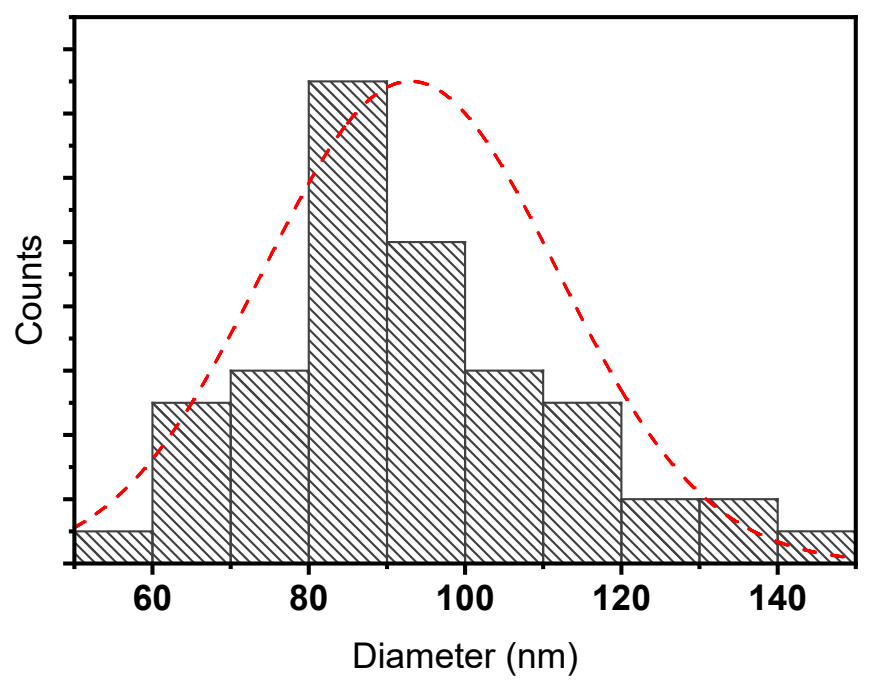

Figure S3. Size distribution analysis of CdS nanoparticles in the CEL side of the BPM. The mean diameter for the CdS is $92 \pm 12 \mathrm{~nm}$. 


\section{Determination of $\mathrm{Pd}(\mathrm{II})$ loading in the BPM-CdS}

\section{a. Absorbance Spectroscopy}

The BPM $\left(4 \mathrm{~cm}^{2}\right)$ was loaded with the same amount of CdS in the CEL side but different loadings of Pd(II) in the AEL side. Five different set of samples were prepared by varying the contact time of the membrane with the $\mathrm{Pd}(\mathrm{II})$ solution. With increasing time, more $\mathrm{Pd}(\mathrm{II})$ was incorporated into AEL.

The concentration of the solution in the AEL was monitored to track the loss of $\mathrm{Pd}(\mathrm{II})^{+}$from the solution. A decrease of the peak corresponding to $\operatorname{Pd}(\mathrm{II})$ solution $\left(\lambda=298 \mathrm{~nm}, \varepsilon=183 \mathrm{M}^{-1} \mathrm{~cm}^{-1}\right)$ during $\mathrm{Pd}^{2+}$ loading exposed to the AEL side of the BPM is seen over time Figure S3. This confirmed the ability of the AEL side to absorb the chlorinated palladium species in the porous network of the membrane via electrostatic interaction.

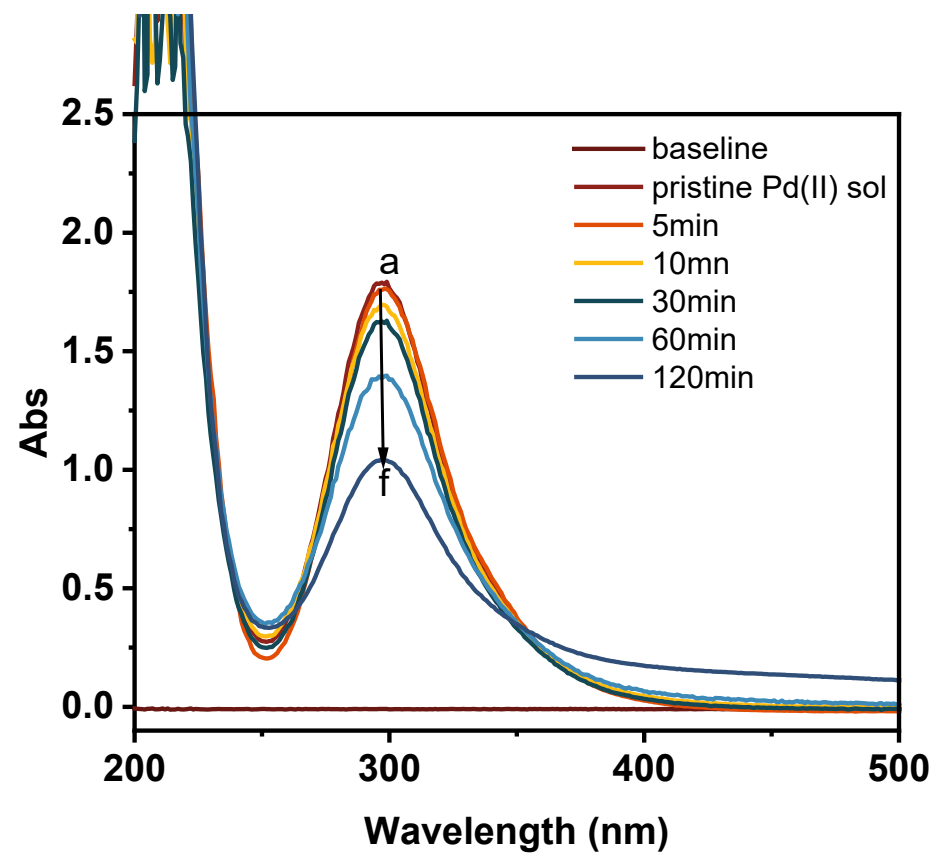

Figure S4. Absorbance spectrum of $\mathrm{Pd}(\mathrm{II})$ solutions starting from (a) pristine solution to (f) solution collected after $120 \mathrm{~min}$ in contact with the AEL side of the membrane.

\section{b. Square Wave Voltammetry Measurements}

For each solution of $\mathrm{Pd}(\mathrm{II})$, before and after the soaking procedure with the BPM-CdS (see Table S1), was diluted ten times to lower the concentration and detect its signal during the analysis. Small amounts of $\mathrm{KCl}$ were added before the measurement to the solution as electrolyte. Scans were taken at a step size of $2.0 \mathrm{mV} / \mathrm{step}$ and with a rate of $25 \mathrm{mV} / \mathrm{s}$ starting from $\mathrm{OV}$ to $-0.9 \mathrm{~V}$ versus $\mathrm{Ag} / \mathrm{AgCl}$ ( $\mathrm{Pt}$ was employed as 
counter electrode). Pd (II) showed a potential signal centered at $0.8 \mathrm{~V}$ (see Figure S5). The current (I) relating to the initial $0.01 \mathrm{M}$ solution of $\mathrm{Pd}\left(\mathrm{NH}_{3}\right)_{4} \mathrm{Cl}_{2}$ (trace a, Figure S4) was used to approximation and calculate the total amount of palladium in the surface of the membrane. As $\mathrm{Pd}^{2+}$ gets incorporated into the film, the measured current decreases (traces b-f, Figure S4) and that decrease can be related to the loading in the AEL side of the membrane (Figure S4B).
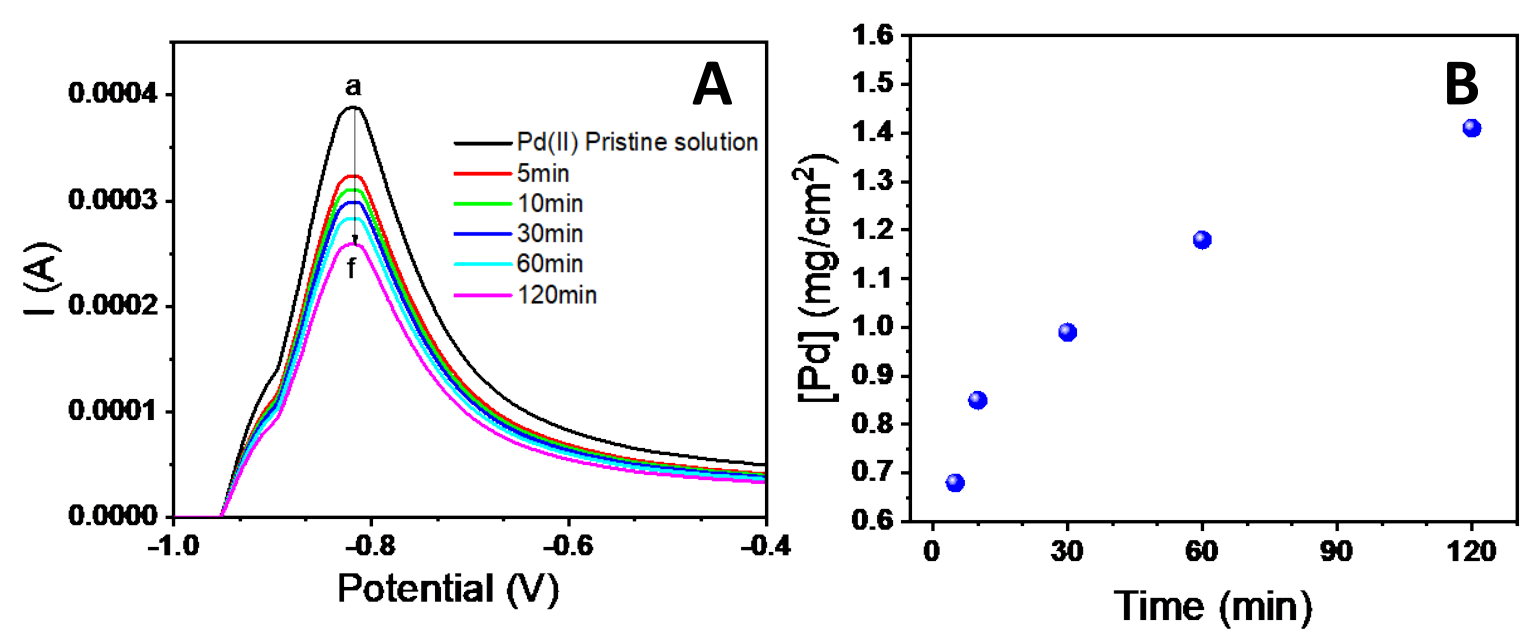

Figure S5. (A) Square wave voltammograms (SQWV) of Pd(II) solution following the loading of the membrane; (a) pristine Pd(II) solution before soaking of BPM (b)-(f) after soaking of membrane (BPM$\mathrm{CdS})$ for different times. (B) The total amount of $\mathrm{Pd}\left(\mathrm{mg} / \mathrm{cm}^{2}\right)$ estimated from the decreased peak in SQWV at different soaking times. 
Table S1. Estimation of palladium quantity $\left(\mathrm{mg} / \mathrm{cm}^{2}\right)$ in the membrane using square wave voltammetry

\begin{tabular}{lllll}
\hline Soaking time & $\Delta \mathrm{I}$ & $\Delta \mathrm{C}$ & $\mathrm{Pd}(\mathrm{II})$ & $\mathrm{Pd}$ \\
& (A) & (M) & moles $/ 4 \mathrm{~cm}^{2}$ & equivalent \\
& & & & $\mathrm{mg} / \mathrm{cm}^{2}$ \\
\hline $5 \mathrm{~min}$ & $6 \mathrm{E}-5$ & $1.6 \mathrm{E}-3$ & $6.4 \mathrm{E}-6$ & $\mathbf{0 . 1 7}$ \\
\hline $10 \mathrm{~min}$ & $7.3 \mathrm{E}-5$ & $2 \mathrm{E}-3$ & $8 \mathrm{E}-6$ & $\mathbf{0 . 2 1}$ \\
\hline $30 \mathrm{~min}$ & $8.4 \mathrm{E}-5$ & $2.3 \mathrm{E}-3$ & $9.3 \mathrm{E}-6$ & $\mathbf{0 . 2 5}$ \\
\hline $60 \mathrm{~min}$ & $1 \mathrm{E}-4$ & $2.7 \mathrm{E}-3$ & $1.1 \mathrm{E}-5$ & $\mathbf{0 . 3 0}$ \\
\hline $120 \mathrm{~min}$ & $1.2 \mathrm{E}-4$ & $3.3 \mathrm{E}-3$ & $1.3 \mathrm{E}-5$ & $\mathbf{0 . 3 4}$ \\
\hline
\end{tabular}




\section{Photocatalytic Experiments}

Reduction of Methyl Viologen

BPM-CdS/Pd was introduced in the H-Cell with $4 \mathrm{~mL}$ of $1 \mathrm{mM}$ of $\mathrm{MV}^{2+}$ in the $\mathrm{AEL}$ side and $4 \mathrm{~mL}$ of EtOH in the CEL side as hole scavengers. The cell compartments were closed with the septa to avoid the presence of oxygen and moisture during the photocatalytic process. The solutions were purged with $\mathrm{N}_{2}$ for 30 minutes. The cell was irradiated with visible light, using a $300 \mathrm{~W}$ Xe-lamp placed $30 \mathrm{~cm}$ away from the sample. A water layer and a cut-off filter $(\lambda>390 \mathrm{~nm})$ was placed between the cell and the light source. The area of the BPM-CdS/Pd exposed to light was $\left(0.785 \mathrm{~cm}^{2}\right)$ The absorbance spectra of the solution were recorded periodically to monitor the formation of $\mathrm{MV}^{+\bullet}$ species for all samples.

Oxidation of 4-Nitro Phenol

BPM-CdS/Pd was introduced in the H-Cell with $4 \mathrm{~mL}$ of $25 \mu \mathrm{M} 4 \mathrm{NP}$ (water solution) in the AEL side of the cell, the $\mathrm{pH}$ of the solution was adjusted to 10 adding $0.2 \mu \mathrm{L}$ of $\mathrm{NaOH}(0.2 \mathrm{M})$. The $\mathrm{CEL}$ side is filled with 4 $\mathrm{mL}$ of EtOH/water (3:1). The cell was clamped and the solution was purged for 30 minutes with $\mathrm{N}_{2}$. The cell was irradiated with a visible light as mentioned above. The absorption spectra were recorded periodically to monitor the degradation of nitrophenol species and the formation of aminophenol in solution species for all samples.

Simultaneous Oxidation and reduction of 4-Chlorophenol and 4-Nitrophenol

BPM-CdS/Pd was introduced in the H-Cell, the CEL side of the cell is filled up with $4 \mathrm{~mL}$ of 4-CP $30 \mu \mathrm{M}$ in water, while the AEL side is filled with $4 \mathrm{~mL}$ of $30 \mu \mathrm{M} 4 \mathrm{NP}(\mathrm{pH} 10)$. The cell compartments were closed with the septa, clamped and purged for 30 min with $\mathrm{N}_{2}$. The CdS in the membrane was excited with the visible light $(\lambda>390 \mathrm{~nm})$. The absorption spectra were recorded periodically to monitor the degradation of chlorophenol (CEL side) and the oxidation of nitro phenol (AEL side). 


\section{Reduction of Methyl Viologen at Low Pd Loadings}

The samples with the lower concentration of PdNPs, with nominal quantity starting from 0.17-0.25 $\mathrm{mg} / \mathrm{cm}^{2}$, in the membrane exhibited relatively low photocatalytic activity to reduce the $\mathrm{MV}^{2+}$. During the first five minutes of irradiation, we noted an increase of the absorbance peak centered at $605 \mathrm{~nm}$ in all cases followed by a slower decrease in the concentration (Figure S6D). The absorbance decrease is due to the competitive equilibrium in solution $\left(\mathrm{MV}^{2+} \leftrightarrow \mathrm{MV}^{+\bullet}\right)$ and the low concentration of $\mathrm{Pd}$ species, which does not allow a continuous electron transfer in the solution.
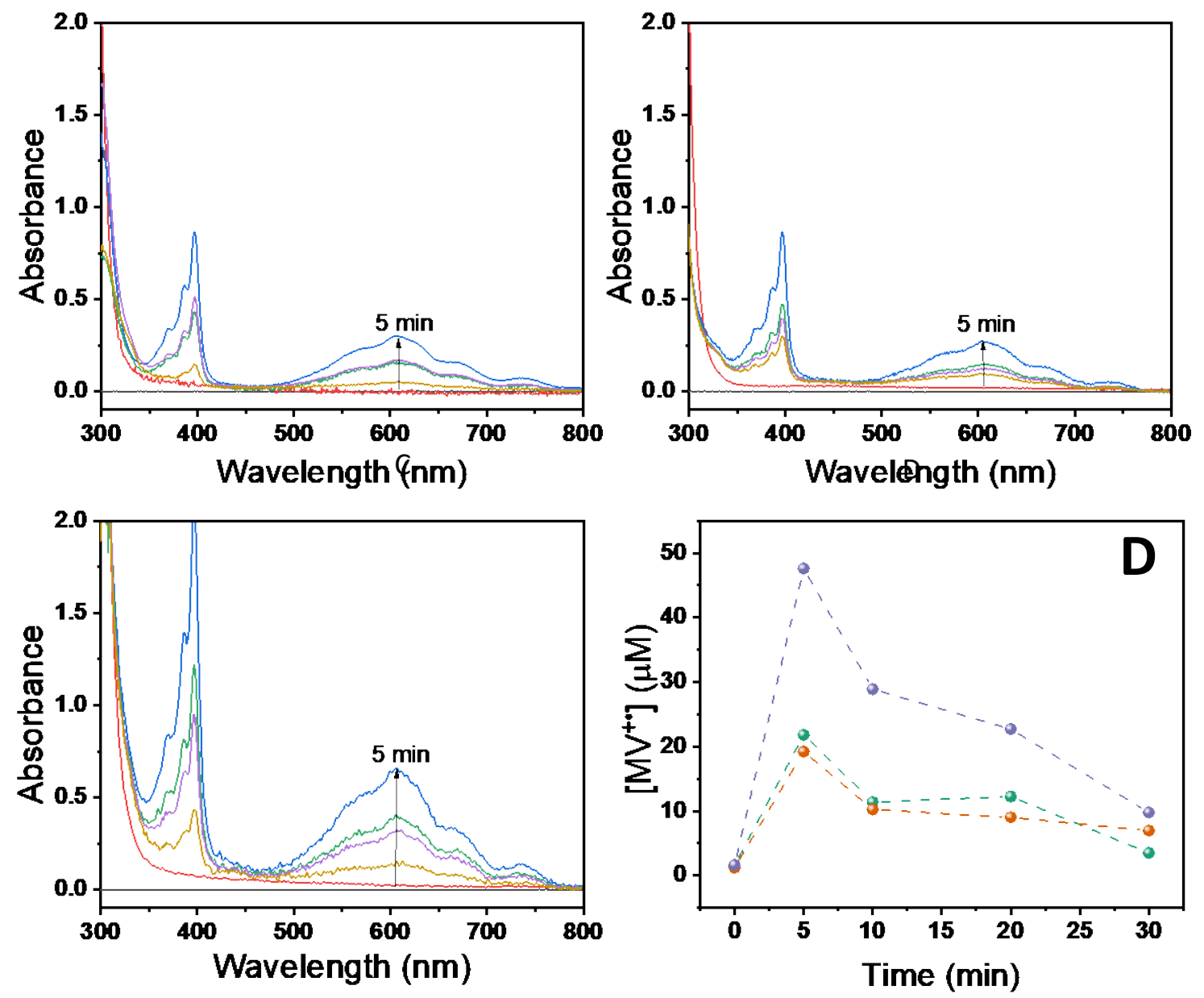

Figure S6. Absorbance spectra recorded during photocatalytic reduction of $\mathrm{MV}^{2+}$ using BPM-CdS/Pd membrane. Pd concentrations in BPM were (A) $0.17 \mathrm{mg} / \mathrm{cm}^{2}$, (B) $0.21 \mathrm{mg} / \mathrm{cm}^{2}$, and (C) $0.25 \mathrm{mg} / \mathrm{cm}^{2}$. (D) Formation and decay of $\mathrm{MV}^{+} \bullet$ radical during the irradiation of $\mathrm{BPM}-\mathrm{CdS} / \mathrm{Pd}$. 
Increasing the concentration of PdNPs in the membrane to $0.25 \mathrm{mg} / \mathrm{cm}^{2}$ the reduction of $\mathrm{MV}^{2+}$ occurred as reported in the Figure $\mathbf{S 7}(\mathbf{A}, \mathbf{B})$ upon $60 \mathrm{~min}$ under irradiation with a rate of $1.03 \times 10^{-6} \mathrm{~min}^{-1}$. The back electron transfer process (after stopping the illumination) occurred with $5.5 \times 10^{-5} \mathrm{~min}^{-1}$ rate constant.
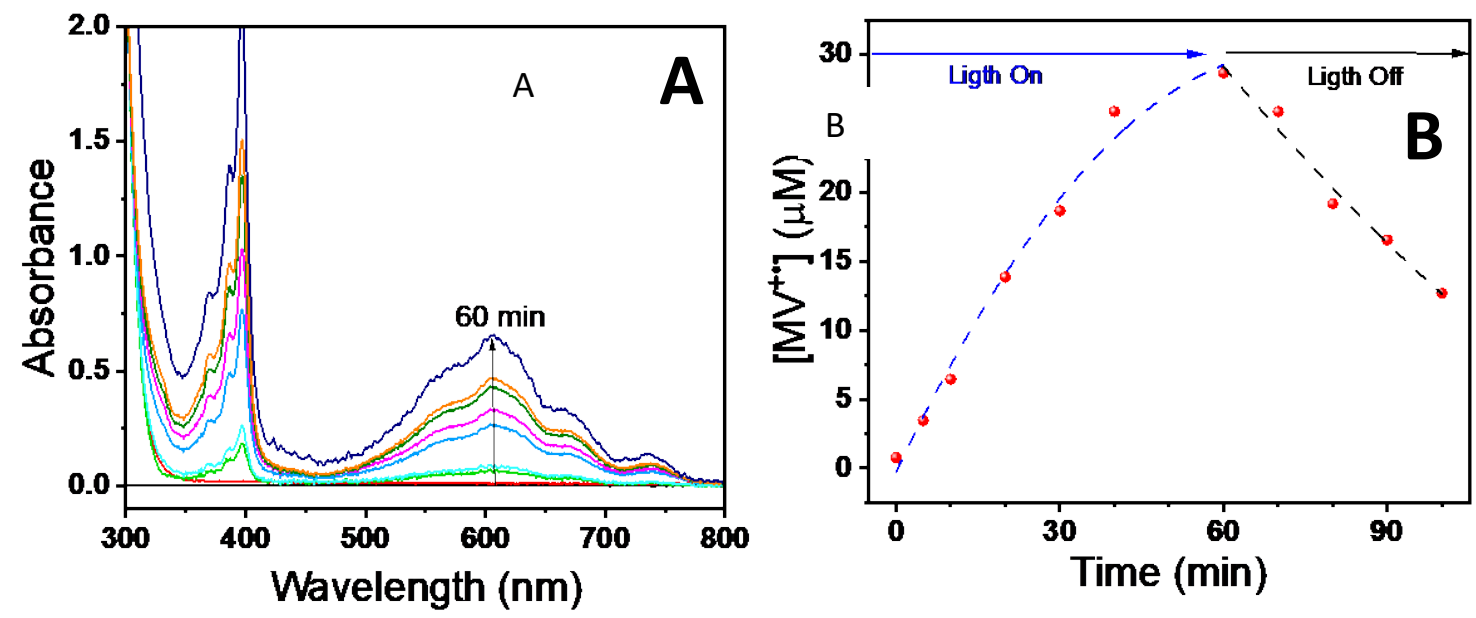

Figure S7. (A) $\mathrm{MV}^{2+}$ reduction under irradiation for $60 \mathrm{~min}$. (B) Formation of $\mathrm{MV}^{+} \cdot$ radical during radiation (light on) and back-electron transfer (with light off).

\section{Reduction of 4-Nitrophenol at low Pd Loadings in BPM-CdS/Pd at low loadings}

The samples with low quantity of PdNPs $\left(0.17-0.25 \mathrm{mg} / \mathrm{cm}^{2}\right)$ were also tested for the photocatalytic reduction of 4-NP in solution. Negligible absorbance changes were detected corresponding to the formation of aminophenol or the degradation of nitrophenol. This further confirms the difficulty in achieving good electron transport between CdS and Pd in the BPM-CdS/Pd with low Pd-loading. 